\title{
Current management of gastric cancer
}

\author{
Antonio Viúdez-Berral ${ }^{1}$, Coro Miranda-Murua ${ }^{2}$, Fernando Arias-de-la-Vega ${ }^{3}$, Irene Hernández-García ${ }^{1}$, \\ Alicia Artajona-Rosino ${ }^{2}$, Álvaro Díaz-de-Liaño ${ }^{2}$ and Ruth Vera-García ${ }^{1}$ \\ ${ }^{1}$ Department of Medical Oncology, ${ }^{2}$ Area of Surgery, Unit of Esophagogastric Surgery, and ${ }^{3}$ Department of Radiotherapy. \\ Complejo Hospitalario de Navarra. Pamplona, Spain
}

\begin{abstract}
Gastric cancer is a disease with high incidence and mortality in our population. The prognosis of patients with this disease is closely related to the neoplasm stage at diagnosis, including the following characteristics of the tumor: extension into the gastric wall thickness, spread to locoregional lymph nodes and the ability to generate distant metastases, as described by the TNM classification.

For localized tumors characterized only by invasion of mucosa or submucosa at diagnosis, survival at 5 years is between 70 and 95\% with exclusive surgical management; however, when extension into the gastric wall is higher and/or there is locoregional nodal involvement, survival decreases to $20-30 \%$ at 5 years.

Currently, at high-volume centers, the extent of gastrectomy is individualized based on several parameters, which in an increasing number of cases allows a total gastrectomy with D2 lymphadenectomy and preservation of the spleen and pancreas. This improved procedure increases the chance of R0 surgery and improves the relationship between resected and affected lymph nodes, resulting in a decreased risk of the long-term locoregional recurrence.

To improve these results, different therapeutic strategies combining chemotherapy or chemoradiotherapy with surgery have been tested. Previously, the Intergroup 0116 clinical trial, published in 2001, which changed clinical practice in the United States, showed that adjuvant chemoradiotherapy improved survival (from 26 to 37 months overall survival) of these patients. In Europe, perioperative chemotherapy has been considered the standard treatment, since the publication of two randomized phase III trials showed an increase at 5 years survival in the group treated with chemotherapy.
\end{abstract}

Key words: Gastric cancer. Gastric cancer surgery. Perioperative chemotherapy. Adjuvant chemotherapy. Adjuvant chemoradiotherapy.
Received: $10-11-11$.

Accepted: 11-11-11.

Correspondence: Antonio Viúdez-Berral. Department of Medical Oncology. Complejo Hospitalario de Navarra. C/ Irunlarrea, 3. 31008. Pamplona, Spain. e-mail: antonio.viudez.berral@navarra.es.
Viudez-Berral A, Miranda-Murua C, Arias-de-la-Vega F, Hernández-García I, Artajona-Rosino A, Díaz-de-Liaño A, Vera-García R. Current management of gastric cancer. Rev Esp Enferm Dig 2012; 104: 134-141.

\section{INTRODUCTION}

During the second half of the last century, gastric cancer has been the most commonly diagnosed gastrointestinal tract tumor in both sexes. Currently, with the increased incidence of colorectal tumors, gastric cancer is now second in both mortality and incidence in developed countries. There are large geographic variations in distribution, between countries and in the regions within them (1). Gastric cancer is diagnosed twice as frequently in men (2).

In 2006, Spain had an estimated rate of 23.04 cases per 100,000 people, which was slightly higher than the EU average. However, when analyzing mortality in Spain, this tumor is fifth in men (behind lung cancer, colorectal, prostate and bladder cancer) and in women (after breast, colorectal, lung and pancreatic cancer). According to the latest data published by the Spanish Statistics Institute (INE), in 2006 gastric cancer was the leading cause of death in 3,544 men and 2,178 women, representing an age-standardized rate in Spain of 13 per 100,000 in men and 5.5 in women. Is also poor, lower than $28 \%$ at 5 years in our country (3).

Further, analysis of the mortality time trend has shown a sharp decline since 1975, at 3\% annually, with a fairly similar pattern in men and women. The geographic distribution of this tumor is characteristic within the state, and there are significant regional differences. Despite the decline in mortality that occurred over the last decades in practically all provinces, the pattern continues to be "coast-interior" (4). Thus, the rates for Castilla-León and towns on the coast of Galicia are among the highest in Europe.

The factors known to contribute to the worldwide gastric cancer epidemic are related to socioeconomic status; therefore, the decline in incidence and mortality rates associated 
with this disease can be interpreted as a consequence of the development of industrialized countries. Socioeconomic status is related to exposure to different factors, including diet, Helicobacter pylori infection, tobacco, and certain occupational exposures. However, a country like Japan having very high rates of stomach cancer indicates that socioeconomic status is not a single variable that adequately accounts for all exposures that increase the risk for gastric cancer. Thus, cultural factors inherent to different lifestyles, including diet, are likely to have considerable importance. This would also help to explain the substantial differences observed between some provinces in Spain. Other risk factors associated with this tumor include a history of partial gastrectomy, previous family history of gastric cancer, pernicious anemia, type A blood and exposure to ionizing radiation (5).

\section{TREATMENT}

The main oncologic treatments of gastric carcinoma are based on surgery, systemic therapy and radiotherapy. Additionally, active palliation treatments are an important part of cancer management, including stents, surgical shunts and supportive measures. The management of gastric cancer requires a multidisciplinary approach (1).

\section{Management of resectable disease}

In our population at the time of diagnosis, only $40 \%$ of patients were diagnosed with resectable disease. In these cases, which were surgically treated, only one third were defined as an early stage (IA and IB); histological analysis of the remaining surgical specimens showed disease that, although resectable, was considered locally advanced (II, III, M0). The other $60 \%$ of patients were not candidates for surgery; half displayed locally advanced unresectable disease, and the other half displayed metastatic disease (6).

Overall, $60 \%$ of patients in whom complete surgical resection was achieved (R0) will relapse. Therefore, in absolute terms, the surgery is only curative $60 \%$ of the time.

The site of recurrence is locoregional in $70 \%$ of cases, peritoneal in $25-50 \%$, hepatic in $30 \%$ and extra-abdominal in $30-50 \%$. Various groups have attempted to lower the recurrence rates by adding various complementary treatments, either after surgery (adjuvant chemo and chemoradiotherapy), before surgery (neoadjuvant chemo and chemoradiotherapy) or before and after surgery (perioperative chemotherapy).

\section{Surgical treatment}

Preoperative staging aims to determine the extension of the disease in order to establish a personalized treatment plan. It is based on the guidelines set by the $7^{\text {th }}$ edition of
Table I.

\begin{tabular}{|c|c|c|c|c|c|c|}
\hline & $N_{0}$ & $\begin{array}{l}N_{1} \\
(1-2)\end{array}$ & $\begin{array}{l}\mathrm{N}_{2} \\
(3-6)\end{array}$ & $\begin{array}{l}N_{3 a} \\
(7-15)\end{array}$ & $\begin{array}{l}N_{3 b} \\
(\geq 16)\end{array}$ & $\begin{array}{l}M_{1} \\
\text { (positive peritonal } \\
\text { cytology included) }\end{array}$ \\
\hline $\begin{array}{l}\mathrm{T}_{1 \mathrm{a}} \text { (lamina propia or } \\
\text { muscularis mucosa) }\end{array}$ & $\mid A$ & IB & $\| A$ & \multirow{2}{*}{\multicolumn{2}{|c|}{$\| B$}} & \multirow{6}{*}{ IV } \\
\hline $\mathrm{T}_{1 \mathrm{~b}}$ (submucosa) & & & & & & \\
\hline $\begin{array}{l}\mathrm{T}_{2} \text { (muscularis propia } \\
\text { layer) }\end{array}$ & IB & $\| \mathrm{A}$ & $\| B$ & \multicolumn{2}{|c|}{ IIIA } & \\
\hline $\mathrm{T}_{3}$ (subserosa layer) & $\| \mathrm{A}$ & $\| \mathrm{B}$ & $\| I I A$ & \multicolumn{2}{|c|}{$\| \mathrm{II}$} & \\
\hline $\mathrm{T}_{4 a}($ serosa $)$ & $\| B$ & $\| \mathrm{II}$ & $\| \mathrm{IIB}$ & \multicolumn{2}{|c|}{$\| I C$} & \\
\hline $\begin{array}{l}T_{4 b} \text { (nearby organs } \\
\text { structures) }\end{array}$ & \multicolumn{2}{|c|}{$\| \mid \mathrm{B}$} & \multicolumn{3}{|c|}{ IIIC } & \\
\hline
\end{tabular}

the TNM classification supported by the UICC and AJCC in 2010 .

The stage in groups according to this classification is shown in table I.

Preoperative diagnosis is based on the confirmation of the disease and the diagnosis of its extension. Endoscopy with biopsy is the test that allows histological confirmation of malignancy. The reliability of endoscopic ultrasound depends on the specialist who performs it (7). This test can have sensitivity for clinical $\mathrm{T}$ staging between 65 $92 \%$ and for $\mathrm{N}$ stage between $50-95 \%$ and can result in a change in therapeutic management in approximately $25 \%$ of cases (8). CT (computed axial tomography) is used for the diagnosis of distant spread of the disease, with a sensitivity for clinical T staging between $43-82 \%$. PET has not shown adequate sensitivity in the preoperative diagnosis of gastric carcinoma; however, it may be useful in association with CT (9).

Exploratory laparoscopy is a preoperative procedure used to classify potentially resectable patients, especially those undergoing neoadjuvant therapy, patients with unexplained elevated markers and patients with linitis plastica. These are several studies that estimate that the possibility of diagnosis of advanced disease with laparoscopy is approximately $30 \%$ (10).

The goal of surgery is the complete resection of disease and locoregional lymph nodes as well as the reconstruction of digestive continuity with maximum safety and minimal complications and/or sequelae. The type of treatment is established by consensus within multidisciplinary units, depending on the anatomic location of tumors, preoperative staging and the comorbidity associated with each patient (1).

Surgically unresectable tumors are those with level 3 or 4 histologic lymph node involvement, according to the 


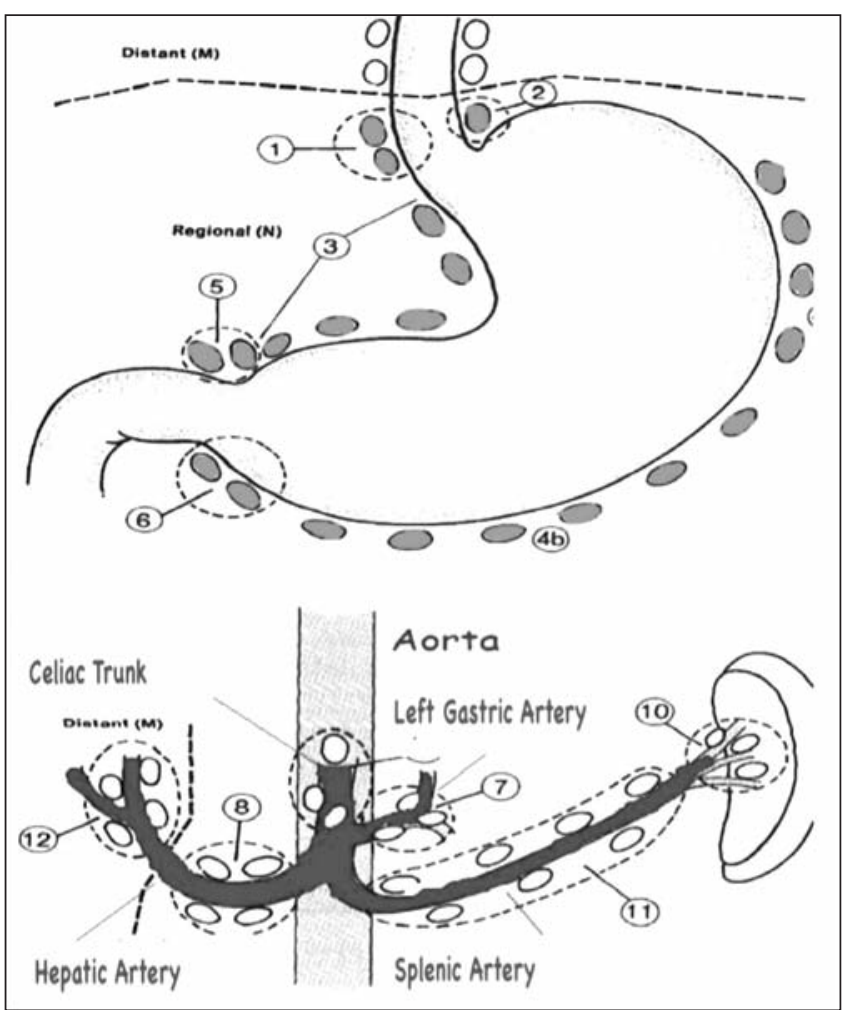

Fig. 1. Nodal groups according to the JRSGC.

Japanese Research Society of Gastric Cancer (11), invasion of major vascular structures and distant metastasis as well as liver and/or peritoneal spread (including positive peritoneal cytology).

According to the UICC, radical surgical treatment aims to remove the entire tumor, resulting in no trace of microscopic disease; this is called R0 surgery and is associated with better control of long-term disease. Surgical treatment is considered R1 when microscopic debris persists or R2 when macroscopic tumor remains.

Surgery with curative intention can be classified into four entities: a) standard resection; b) non-standard resection, in which the expanse of gastrectomy and/or lymphadenectomy was modified according to certain characteristics of the tumor; c) modified resection, which reduces the extent of gastrectomy and/or lymphadenectomy; or d) extended gastrectomy, which provides in bloc resection of adjacent organs or lymph node dissection that are dissected at the lymph node level above D2 (12). Palliative resection is applied only to the complications caused by the primary tumor, including relapse either in the form of bleeding or obstruction.

In antral tumors, subtotal gastrectomy has shown identical results in survival and mortality to those of total gastrectomy, with a lower complication rate and fewer nutritional disorders $(13,14)$. The gastric cancer guidelines recommend treatment of gastric cancer with a macroscopic margin from the edge of the tumor to the stomach section of at least $5 \mathrm{~cm}(1,15,16)$. A microscopic involvement of resection margins is a factor for worse prognosis that increases risk of local relapse and thus lowers survival $(17,18)$. Therefore, in the case of threatened margins into subtotal gastrectomy or total gastrectomy by cardial tumor, an intraoperative margins resection study was recommended.

Several randomized trials have shown that prophylactic resection of the spleen should not be performed because it morbidity without improvement in rates $(19,20)$. In bloc resection of adjacent organs is only recommended when the tumor is directly invasive because this resection itself increases morbidity and mortality, which is only acceptable if R0 surgery is accomplished.

Lymph-node dissection levels are defined according to the JRSGC classification (11) and are also recommended by the AJCC and IUAC. This classification defines 16 nodal groups (Fig. 1): level 1 (N1), which includes the nodes from the lesser curvature (groups 1,3,5) and the greater curvature (groups 2, 4, 6) and level 2, which includes lymph nodes of the left gastric artery (group 7), common hepatic artery (group 8), celiac trunk (group 9), splenic hilum (group 10) and splenic artery (group 11). Notably, the latest edition of the Japanese Classification subdivides group 11 lymph nodes into «11p», defined as those from the origin of the splenic artery to mid pancreatic body, and «11d», defined as periarterial nodes from the mid-pancreatic body to splenic hilum (21).

Extension of the lymphadenectomy and preoperative definition of tumoral lymph node (22) are widely debated topics in literature due to their impact on survival and their use as quality control measure of surgical technique. To perform an adequate D1 lymphadenectomy, which is necessary for correct postoperative staging, a minimum of 15 nodes must be analyzed, and more than 20 when it performing a D2 lymphadenectomy (23).

Asiatic working groups have been the main promoters of the analysis of detailed lymph node dissections. In these countries total gastric resection with D2 lymphadenectomy is the treatment of choice. In a Japanese randomized controlled trial, JCOG9501, D2 lymphadenectomy was compared to extended D2 lymphadenectomy, including para-aortic nodal dissection (D3). The results of this study demonstrated that the fiveyear survival after extended lymphadenectomy was similar $(70,3 \%)$ to that after D2 lymphadenectomy $(69,2 \%)$, noting a higher morbidity in the first group (24). Another trial showed higher survival after D2 lymphadenectomy extended to para-aortic nodes compared with D1 lymphadenectomy only (25).

Paradoxically, these data published by Japanese researchers have not been reproduced by trials in Western countries. In the trial carried out by the British Cooperative Group that compared D2 with D1 lymphadenectomy, the five-year survival was similar (33vs. 31\%), though there was higher morbidity in the group in which a D2 lymphadenectomy was performed (26). Similar results were published by other groups (27-30). Among them, a trial carried out by the Dutch Gastric Cancer Group stands out. 
That study, which compared D2 with D1 lymphadenectomy, showed a higher morbidity (43vs. 25\%) and postoperative mortality (10 vs. 4\%) in the D2 lymphadenectomy group, without differences in cumulative five-year survival (35 vs. $30 \%$ ) (28). However, in that trial, a 15-year follow-up showed a lower rate of local recurrence and disease-related mortality in the D2 lymphadenectomy group compared to the D1 group. Importantly, there was a difference in patients with N2 involved nodes (19 vs. 0\%) (31). Factors related to higher morbidity in the D2 group were above age 65 years old, male gender, type of gastrectomy and performance of a splenectomy and/or pancreatectomy. The increase in postoperative mortality secondary to splenopancreatectomy obscures the potential benefit of D2 lymphadenectomy over D1 $(19,20,31)$. For this reason, different groups advocate D2 lymphadenectomy with splenopancreatic preservation to preserve 10 and $11 \mathrm{~d}$ node stations, except for tumors in the greater curvature, to those that directly invade these organs or to those with metastatic nodes in these node stations. In the last guide from the Japanese Gastric Cancer Association in 2010, en-bloc splenectomy was considered only for clinical T2-T4 tumors invading the greater curvature or cardial tumors. It is not recommended for tumors of any other localization until conclusive results can be obtained from ongoing trials (16).

Laparoscopic resection of gastric tumors offers unquestionable benefits over open surgery, including less blood loss, better postoperative analgesic control, shorter hospital stays and quicker return to routine life. In this regard, a prospective European trial (32) and a Spanish meta-analysis (33) suggest similar results to the laparoscopic procedure in terms of survival and postoperative morbidity and mortality compared to the open procedure (30). However, more prospective trials are needed to gather a higher number of cases and obtain long-term results regarding disease control $(34,35)$.

In our institution, the strategy of surgical treatment with curative intention in patients with distal tumors smaller than 3 centimeters in size without serosal invasion and with intestinal histology is subtotal gastrectomy. In the rest of cases, total gastrectomy with transit reconstruction with a defunctionalized Y-en-Roux limb is performed. In those clinically diagnosed with $\mathrm{T} 1$ tumors or in elderly patients, the selected gastric resection is associated with D1 lymphadenectomy. Finally, in those cases clinically T2-T4 or $\mathrm{N}(+)$, depending on age, the selected gastrectomy is performed along with a D2 lymphadenectomy with splenopancreatic preservation, with the exception of those cases previously discussed that involve the greater curvature, direct invasion of said organs or has nodal involvement of 10 and/or 11d nodal statios; in these cases, splenopancreatic resection becomes necessary (36).

\section{Adjuvant chemotherapy}

Systemic treatment of gastric cancer has led to the development of different treatment strategies in the West and
East. The drugs used in Japan, Korea and other Asian countries have demonstrated a different kinetic behavior in Caucasian populations of the West (37). This is significant because polymorphism differences between the two populations affect the tolerability and efficacy of these drugs.

Over the past three decades, multiple phase III trials have been published comparing adjuvant chemotherapy versus observation with discrepant results. Two studies have broken this trend. The first trial conducted on 1,059 patients with resected gastric cancer and D2 lymphadenectomy with stage II-III disease showed a significant increase in survival in the arm that received adjuvant S-1 (an oral fluoropyrimidine) compared with surgery alone (3-year survival: 80 versus $70 \%$, HR: $0.68,95 \%$ CI 0.52 to $0.87, \mathrm{p}=0.003$ ) (38). These results must be confirmed in the Western population. The second study, which was recently published and called CLASSIC, justifies the application of the XELOX scheme (capecitabine and oxaliplatin) for 8 cycles after surgery in stage IIIA and IIIB disease, showing an absolute decline in the event of progression at 3 years to be $14 \%$ (39). In the last few years, there have been several meta-analyses aimed at answering this question, and they all suggest that adjuvant chemotherapy could provide a small benefit in survival, estimated between 3 and $8 \%$ in absolute terms (40-45). One study that was notable for the number of patients analyzed is the GASTRIC meta-analysis (45). This study showed an absolute benefit in survival of $5.8 \%$ at 5 years (from 49.6 to $55.3 \%$ ) and $7.4 \%$ at 10 years (from 37.5 to $44.9 \%$ ) in patients treated with adjuvant chemotherapy, mainly when it was based on fluoropyrimidines.

\section{Adjuvant chemoradiotherapy}

There have not been major developments following the publication in 2001 of phase III SWOG 9008/INT 0116 (46), in which 556 patients with adenocarcinoma of the stomach or esophagogastric junction (stage IB to IV-M0) subjected to curative resection, were randomized to surgery alone versus surgery followed by chemo-radiotherapy (5fluorouracil bolus-5FU- plus leucovorin). In this study, it was observed that the application of adjuvant therapy resulted in a significant increase in disease-free survival and overall survival at 3 years. These results were confirmed after a follow-up of more than 10 years, with a HR of $1.32(\mathrm{p}=0.004)$ for survival and $1.51(\mathrm{p}<0.001)$ for disease-free survival. This benefit was maintained in all subgroups except in the diffuse histological subtype (47). The limitations of this study were focused on the type of surgery performed because in $54 \%$ of patients, this was suboptimal (less than D1 lymph node dissection), raising the question of whether postoperative chemoradiotherapy could have offset the low nodal resection in most cases. To clarify this issue, a subgroup analysis of the INT0116 trial was published in 2002 (48). This showed that the survival benefit of adjuvant chemo-radiotherapy remained 
similar in the D0 and D1 lymph node dissection groups, while survival benefits in the D2 dissection group were doubtful; however, the small number of patients in this last subgroup made it difficult to draw exhaustive conclusions. An observational Korean study on more than 500 patients (12) showed the benefit of adjuvant chemoradiotherapy even after D2 surgery. Studies have shown that the addition of more cytotoxic drugs to 5FU therapy, according to the MacDonald scheme, does not translate into a survival benefit $(49,50)$.

The planning of radiotherapy fields requires experience and a quality assurance system. Radiotherapy is influenced by its conformation in 3D (3D-CRT) or intensity modulated radiotherapy (IMRT), and these technologies have been shown to reduce toxicities. A total radiation dose $45 \mathrm{~Gy}$ is set to run in 25 fractions of $1.8 \mathrm{~Gy}$. The delimitation of volumes must meet the guidelines established by the RTOG and EORTC and include the tumor bed, celiac lymph nodes and para-aortic nodes.

\section{Perioperative treatment}

Following the publication of the final results of the English phase III MAGIC study (51), which showed an increase in cumulative survival at 5 years of $13 \%$, many authors consider the classical ECF (epirubicin, cisplatin and 5FU) perioperative cocktail used in this study as the new standard treatment in this setting.

On the other hand, the ACCORD group presented the results of the FFCD 9703 study (52), which demonstrated that the administration of cisplatin and 5FU also increased perioperative progression-free survival (PFS) and overall survival in patients with resectable gastric adenocarcinoma compared with the control group. These results are very similar to those observed in the MAGIC study.

Two recent meta-analyses examined the role of neoadjuvant chemotherapy. In the first, a reduction in absolute risk of death at 5 years of $32 \%$ was observed in favor of neoadjuvant treatment (53). In the second, the decrease in risk of death at 5 years was lower (only 18\%) at the expense of patients with tumors at the esophagogastric junction treated with preoperative therapy (54). Based on the results of the REAL-2 study, the substitution of cisplatin by oxaliplatin and $5 \mathrm{FU}$ by capecitabine ca be performed successfully (55).

\section{Treatment of advanced disease}

Advanced gastric cancer cases are defined as those in which the disease is unresectable, including either locally advanced disease (30\% of cases) or metastatic disease (another 30\%) and patients who have relapsed (60\% of resected cases). Globally, approximately $84 \%$ of patients with gastric cancer have advanced disease over the course of their illness.

\section{First-line treatment}

Palliative chemotherapy has a clear impact on survival when compared with the best supportive care $(\mathrm{HR}=0.39$, 95 CI: 0.28-0.52), generating further improvement in the quality of life of those patients who are treated. This benefit is observed mainly in patients with preserved functional status. Currently, no chemotherapy regimen can be considered standard (56-58), and thus, the choice depends essentially on the patient's profile.

Between 1997 and 2000, several studies showed that cisplatin-based regimens were superior to other schemes without cisplatin $(59,60)$. Both $\mathrm{CF}$ (cisplatin/5FU) and ECF (4-epirubicin, cisplatin and 5FU) can be considered as reference regimens. These schemes provide radiological response rates, ranging between 20 and $40 \%$, and very few complete responses (approximately 5\%). Unfortunately, this benefit usually lasts for a short time, with median time to progression after approximately 4-5 months and a median survival of only 7-10 months. As noted above, this benefit is considered for patients with good performance status, despite the toxicity and inconvenience of treatment, especially with cisplatin schemes, which is significant.

The V-325 study (61) compared the DCF regimen (docetaxel, cisplatin and 5FU) with $\mathrm{CF}$. The primary endpoint was the time to progression, and overall survival was emphasized among the secondary objectives. The study was positive for its main objective, whose median was 5.6 months in the TCF arm compared to 3.7 months in the CF $\mathrm{arm}$. There were also statistically superior outcomes in the TCF arm with respect to survival, survival at 2 years and response rate. As for toxicity, grade 3-4 neutropenia, febrile neutropenia and diarrhea were more common than cisplatin/5FU in the TCF group. It is noteworthy that febrile neutropenia decreased from 30 to $12 \%$ in the TCF-treated group with the administration of colony stimulating factors. This toxicity requires essentially adding docetaxel in patients selected for their good performance status.

The REAL-2 study (62) compared four different schemes, replacing cisplatin with oxaliplatin and 5FU with capecitabine. There were no statistically significant differences in the response rates or progression-free survival. The EOX scheme (epirubicin, oxaliplatin and capecitabine) was superior to ECF in overall survival (11.2 vs. 9.9 months, $\mathrm{p}=0.02$ ). The response rates were $40.7,46.4,42.4$ and $47.9 \%$ for the ECF, ECX, EOF and EOX therapy, respectively. Other studies have demonstrated the noninferiority noninferiority of capecitabine versus $5 \mathrm{FU}$ and oxaliplatin versus cisplatin (63).

In the TOGA study (64), $22.1 \%$ of the patients analyzed (810 patients) were positive for c-erb-2 (IHC $3+$ or FISH+). Positivity was higher in the Lauren intestinal subtype (32\%) and in tumors of the esophagogastric junction (32.2\%). The combination of trastuzumab with chemotherapy in patients who were c-erb-2-positive gave a survival increase of nearly 3 months (13.8 vs. 11.1 months). That benefit was substan- 
tially greater in patients who were c-erb- 2 IHC $2+$ and $\mathrm{FISH}+$ and IHC $3+$. In these patients, a median survival of 16 months was achieved. This benefit also increased the radiological response rate and progression-free interval without further toxicity.

\section{Second-line treatment}

The application of a second line of treatment may be justified in patients with a consistently maintained performance status. Two randomized trials have assessed the role of second-line chemotherapy. The first, a German study, was stopped prematurely due to lack of recruitment. Even so, this study showed a survival benefit in patients treated with tri-weekly irinotecan (HR $0.48,95 \%$ CI 0.23 to $0.92, \mathrm{p}=$ $0.023)(65)$. The second was a Korean randomized study for which data have been recently presented. That study demonstrated the benefit of second-line irinotecan or docetaxel ((HR 0.64, 95\% CI 0.466-0.86392, p = 0.009) (66). The identification of variables such as functional status, baseline hemoglobin, time to progression after first-line therapy (more or less than 6 months), levels of CEA and the number of metastatic sites (more or less than 3 ) help to establish the expected benefit of a second line treatment (67-69).

\section{ACKNOWLEDGEMENTS}

We would like to thank Dr. Miguel Muñoz for his collaboration in the drafting of this article.

\section{REFERENCES}

1. Allum WH, Blazeby JM, Griffin SM, Cunningham D, Jankowski JA, Wong R. Guidelines for the management of oesophageal and gastric cancer. Gut 2011;60:1449-72.

2. Cabanes Domenech A, Pérez-Gómez B, Aragonés N, Pollán M, LópezAbente G. La situación del cáncer en España, 1975-2006. Madrid: Instituto de Salud Carlos III, 2009.

3. Sant M, Allemani C, Santaquilani M, Knijn A, Marchesi F, Capocaccia R. EUROCARE-4. Survival of cancer patients diagnosed in 1995-1999. Results and commentary: Eur J Cancer 2009;45:931-91.

4. Lopez-Abente G, Pollan M, Escolar A, Errezola M, Abraira V. Atlas de mortalidad por cáncer y otras causas en España, 1978-1992. Madrid: Instituto de Salud Carlos III; 2001.

5. Cunningham D, Jost LM, Purkalne G, Oliveira J, Coordinating authors for the ESMO Guidelines Task Force: ESMO Minimum Clinical Recommendations for diagnosis, treatment and follow-up of gastric cancer. Ann Oncol 2005;16(Supl.1):22-3.

6. Brennan MF, Karpeh MS Jr. Surgery for gastric cancer: the American view. Semin Oncol 1996;23:352-9.

7. Matsumoto Y, Yanai H, Tokiyama H, Nishiaki M, Higaki S, Okila K. Endoscopic ultrasonography for diagnosis os submucosal invasion in early cancer. J Gastroenterol 2000;35:326-31.

8. Repiso A, Gómez-Rodríguez R, López-Pardo R, Lombera MM, Romero $\mathrm{M}$, Aranzana A, et al. Usefulness of endoscopic ultrasonography in preoperative gastric cancer staging: diagnostic yield and therapeutic impact. Rev Esp Enferm Dig 2010;102:413-20.

9. Kwee RM, Kwee TC. Imaging in assessing lymph node status in gastric cancer. Gastric Cancer 2009;12:6-22.
10. Sarela AI, Lefkowitz R, Brennan MF, Karpeh MS. Selection of patients with gastric adenocarcinoma for laparoscopic staging. Ann J Surg 2006;191:134-8.

11. Japanese Gastric Cancer Association. Japanese classification of gastric carcinoma. $2^{\text {nd }}$ English ed. Gastric Cancer 1998;1:10-24.

12. Kim S, Lim DH, Lee J, Kang WK, MacDonald JS, Park CH, et al. An observational study suggesting clinical benefit for adjuvant postoperative chemoradiation in a population of over 500 cases after gastric resection with D2 nodal dissection for adenocarcinoma of the stomach. Int J Radiat Oncol Biol Phys 2005;63:1279-85.

13. Bozzetti F, Marubini E, Bonfanti G, Miceli R, Piano C, Gennari L, et al. Subtotal versus total gastrectomy for gastric cancer: five-year survival rates in a multicenter randomized Italian trial. Italian Gastrointestinal Tumor Study Group. Ann Surg 1999;230:170-8.

14. Gouzi JL, Huguier M, Fagniez PL, Launois B, Flamant Y, Lacaine F, et al. Total versus subtotal gastrectomy for adenocarcinoma of the gastric antrum. A French prospective controlled study. Ann Surg 1989;209:162-6.

15. Okines A, Verheij M, Allum W, Cunningham D, Cervantes A. Gastric cancer: ESMO Clinical Practice Guidelines for diagnosis, treatment and follow-up. On behalf of the ESMO Guidelines Working Group. Annals of Oncology 2010;21(Supl.5):50-4.

16. Japanese Gastric Cancer Association. Japanese gastric cancer treatment guidelines 2010 (ver.3). Gastric Cancer 2011;14:113-23.

17. Songun I, Bonenkamp JJ, Hermans J, van Krieken JH, van de Velde CJ. Prognostic value of resection-line involvement in patients undergoing curative resections for gastric cancer. Eur J Cancer 1996;32: 433-7.

18. Kim SH, Karpeh MS, Klimstra DS, Leung D, Brennan MF. Effect of microscopic resection line disease on gastric cancer survival. J Gastrointest Surg 1999;3:24-33.

19. Csendes A, Burdiles P, Rojas J, Braghetto I, Diaz JC, Maluenda F. A prospective randomized study comparing D2 total gastrectomy versus D2 total gastrectomy plus splenectomy in 187 patients with gastric carcinoma. Surgery 2002;131:401-7.

20. Yu W, Choi GS, Chung HY. Randomized clinical trial of splenectomy versus splenic preservation in patients with proximal gastric cancer. Br J Surg 2006; $93: 559-63$.

21. Japanese classification of gastric carcinoma. $3^{\text {rd }}$ English ed. Gastric Cancer 2011;14:101-12.

22. Espín F, Bianchi A, Llorca S, Pulido L, Felíu J, de-la-Cruz J, et al Large lymph node size harvested as prognostic factor in gastric cancer? Rev Esp Enferm Dig 2010;102:169-75.

23. Schwarz RE, Smith DD. Clinical impact of lymphadenectomy extent in resectable gastric cancer of advanced stage. Ann Surg Oncol 2007; 14:317-28.

24. Sasako M, Sano T, Yamamoto S, Kurokawa Y, Nashimoto A, Kurita A, et al. D2 lymphadenectomy alone or with para-aortic nodal dissection for gastric cancer. N Engl J Med 200;359:453-62.

25. Wu C-W, Hsiung CA, Lo SS, Hsieh MC, Chen JH, Li AF, et al. Nodal dissection for patients with gastric cancer: a randomised controlled trial. Lancet Oncol 2006;7:309-15.

26. Cuschieri A, Weeden S, Fielding J, Bancewicz J, Craven J, Joypaul V, et al. Patient survival after D1 and D2 resections for gastric cancer: long-term results of the MRC randomized surgical trial. Surgical Cooperative Group. Br J Cancer 1999;79:1522-30.

27. Dent DM, Madden MV, Price SK. Randomized comparison of R1 and R2 gastrectomy for gastric carcinoma. Br J Surg 1988;75:110-2.

28. Hartgrink HH, van de Velde CJ, Putter H, Bonenkamp JJ, Klein Kranenbarg E, Songun I, et al. Extended lymph node dissection for gastric cancer: who may benefi t? Final results of the randomized Dutch gastric cancer group trial. J Clin Oncol 2004;22:2069-77.

29. Robertson CS, Chung SC, Woods SD, Griffin SM, Raimes SA, Lau JT, et al. A prospective randomized trial comparing R1 subtotal gastrectomy with R3 total gastrectomy for antral cancer. Ann Surg 1994:220:176-82.

30. Degiuli M, Sasako M, Calgaro M, Garino M, Rebecchi F, Mineccia M, et al. Morbidity and mortality after D1 and D2 gastrectomy for cancer: interim analysis of the Italian Gastric Cancer Study Group (IGCSG) randomized surgical trial. Eur J Surg Oncol 2004;30:303-8.

31. Songun I, Putter H, Kranenbarg EM, Sasako M, van de Velde CJ. Surgical treatment of gastric cancer: 15 years follow-up results of the randomized nationwide Dutch D1D2 trial. Lancet Oncol 2010;11:439-49. 
32. Huscher CG, Mingoli A, Sgarzini G, Sansonetti A, Di Paola M, Recher A, et al. Laparoscopic versus open subtotal gastrectomy for distal gastric cancer: five-year results of a randomized prospective trial. Ann Surg 2005;241:232-7.

33. Martínez-Ramos D, Miralles-Tena JM, Cuesta MA, Escrig-Sos J, Van der Peet D, Hoashi JS, et al. Laparoscopy versus open surgery for advanced and resectable gastric cancer: a meta-analysis. Rev Esp Enferm Dig 2011;103:133-41.

34. Memon MA, Butler N, Memon B. The issue of lymphadenectomy during laparoscopic gastrectomy for gastric carcinoma. World J Gastrointest Oncol 2010;2:65-7.

35. Shinohara T, Kanaya S, Taniguchi K, Fujita T, Yanaga K, Uyama I. Laparoscopic total gastrectomy with D2 lymph node dissection for gastric cancer. Arch Surg 2009;144:1138-42.

36. Díaz de Liaño A, Yárnoz C, Artieda C, Aguilar R, Viana S, Artajona A, et al. Results of R0 surgery with D2 lymphadenectomy for the treatment of localised gastric cancer. Clin Transl Oncol 2009;11:178-82.

37. Ajani JA, Faust J, Ikeda K, Yao JC, Anbe H, Carr KL, et al. Phase I pharmacokinetics study of S1 plus cisplatin in patients with advanced gastric carcinoma. J Clin Oncol 2005;3:6957-65.

38. Sakuramoto S, Sasako M, Yamaguchi T, Kinoshita T, Fujii M, Nashimoto A, et al. Adjuvant chemotherapy for gastric cancer with S1, an oral fluoopyrimidine. N Eng J Med 2007;357:1810-20.

39. Bang Y, Kim YW, Yang H, Chung HC, Park YK, Lee KH, et al. Adjuvant capecitabine and oxaliplatin for gastric cancer after D2 gastrectomy (CLASSIC): a phase 3 open-label, randomised controlled trial. Lancet. 2012;379:315-21

40. Hermans J, Bonenkamp JJ, Boon MC, Bunt AM, Ohyama S, Sasako $\mathrm{M}$, et al. Adjuvant therapy after curative resection for gastric cancer: meta-analysis of randomized trials. J Clin Oncol 1993;11:1441-7.

41. Earle CC, Maroun JA. Adjuvant chemotherapy after curative resection for gastric cancer in non-Asian patients: revisiting a meta-analysis of randomised trials. Eur J Cancer 1999;35:1059-64.

42. Mari E, Floriani I, Tinazzi A, Buda A, Belfiglio M, Valentini M, et al. Efficacy of adjuvant chemotherapy after curative resection for gastric cancer: a meta-analysis of published randomised trials. A study of the GISCAD (Gruppo Italiano per lo Studio dei Carcinomi dell Apparato Digerente. Ann Oncol 2000;11:837-43.

43. Panzini I, Gianni L, Fattori PP, Tassinari D, Imola M, Fabbri P, et al. Adjuvant chemotherapy in gastric cancer: A meta-analysis of randomized trials and a comparison with previous meta-analysis. Tumori 2002;88:21-7.

44. Janunger KG, Hafstrom L, Glimelius B. Chemotherapy in gastric cancer: a review and updated meta-analysis. Eur J Surg 2002;168:597-608.

45. Sakamoto J Paoletti X, on behalf of the Global Adv/Adj Stomach Tumor Research through International Collaboration (GASTRIC). Meta-analyses of randomized trials assessing the interest of postoperative adjuvant chemotherapy in gastric cancer. J Clin Oncol 2008;26:18S(abstr 4543).

46. Macdonald JS, Smalley SR, Benedetti J, Hundahl SA, Estes NC, Stemmermann GN, et al. Chemoradiotherapy after surgery compared with surgery alone for adenocarcinoma of the stomach or gastroesophageal junction. N Engl J Med 2001;345:725-30.

47. Macdonald JS, Benedetti J, Smalley S, Haller D, Hundahl S, Jessup J, et al. Chemoradiation of resected gastric cancer: a 10-year follow-up of the phase III trial INT0116 (SWOG 9008). J Clin Oncol 2009; 27(Supl.15):Abstract 4515

48. Macdonald JS, Smalley S, Benedetti J. Postoperative combined radiation and chemotherapy improves disease-free survival (DFS) and overall survival (OS) in resected adenocarcinoma of the stomach and gastroesophageal junction: Update of the results of Intergroup Study INT0116 (SWOG 9008). ASCO 2004 (abstr 6).

49. Ortidura M, De Vita F, Muto P, Vitiello F, Murino P, Lieto E, et al. Adjuvant chemoradiotherapy in patients with stage III or IV radically resected gastric cancer: A pilot study. Arch Surg 2010;145:233-8.

50. Leong T, Joon DL, Willis D, Jayamoham J, Spry N, Harvey J, et al. Adjuvant chemoradiation for gastric cancer using epirubicin, cisplatin and 5 -fluorouracil before and after three-dimensional conformal radiotherapy with concurrent infusional 5-fluorouracil: a multicenter study of the Trans-Tasman Radiation Oncology Group. Int J Radiat Oncol Biol Phys 2011;79:690-5.

51. Cunningham D, Allum W H, Stening SP, Weeden S. Perioperative chemotherapy versus surgery alone for resectable gastroesophageal cancer. N Engl J Med 2006;355:11-20.
52. Ychou M, Boige V, Pignon JP, Conroy T, Bouché O, Lebreton G, et al. Perioperative chemotherapy compared with surgery alone for resectable gastroesophageal adenocarcinoma: an FNCLCC and FFCD multicenter phase III trial. J Clin Oncol 2011;29:1715-21.

53. Li H, Cao Y, Zhai L, et al. Meta-analyses of randomized trials assessing the effect of neoadjuvant chemotherapy in locally advanced gastric cancer. J Clin Oncol 2010;28(Supl.7):Abstract 4042.

54. Ronellenfitsch U, Schwarbach M, Hofheinz R, Kienle P, Hohenberger $\mathrm{P}$, Jensenet $\mathrm{K}$, et al. Meta-analysis ofpreoperative chemotherapy (CTX) versus primary surgery for locoregionally advanced adenocarcinoma of the stomach, gastroesophageal junction, and lower esophagus (GE adenocarcinoma). J Clin Oncol 2010;28(Supl.7):Abstract 4022.

55. Van Cutsem E, Dicato M, Geva R, Arber N, Bang Y, Benson A, et al The diagnosis and management of gastric cancer: expert discussion and recommendations from the 12th ESMO/World Congress on Gastrointestinal Cancer, Barcelona, 2010. Ann Oncol. 2011;Supl.5:1-9.

56. Wagner AD, Grothe W, Haerting J, Kleber G, Grothey A, Fleig WE, et al. Chemotherapy in advanced gastric cancer: A systematic review and meta-analysis based on aggregate data. J Clin Oncol 2006;24:2903-9.

57. Sastre J, García-Saenz JA, Díaz-Rubio E. Chemotherapy for gastric cancer. World J Gastroenterol 2006;14:204-13.

58. Rivera F, Vega-Villegas ME, López-Brea M. Chemotherapy of advanced gastric cancer. Cancer Treatment Reviews 2007;33:315-24.

59. Webb A, Cunningham D, Scarffe JH, Harper P, Norman A, Joffe JK, et al. Randomized trial comparing epirubicin, cisplatin, and 5FU vs. $5 \mathrm{FU}$, doxorubicin, and methotrexate in advanced esophagogastric cancer. J Clin Oncol 1997; 15:261-7.

60. Vanhoefer U, Rougier P, Wilke H, Ducreux MP, Lacave AJ, Van Cutsem E, et al. Final results of a randomized phase III trial of sequential high-dose methotrexate, fluorouracil, and doxorubicin versus etoposide, leucovorin, and $5 \mathrm{FU}$ versus infusional $5 \mathrm{FU}$ and cisplatin in advanced gastric cancer: a trial of the European Organization for Research and Treatment of Cancer Gastrointestinal Tract Cancer Cooperative Group. J Clin Oncol 2000;18:2648-57.

61. Van Cutsem E, Moiseyenko VM, Tjulandin S, Majlis A, Constenla M, Boni C, et al. Phase III study of docetaxel and cisplatin plus fluorouracil compared with cisplatin and fluorouracil as first-line therapy for advanced gastric cancer: a report of the V325 Study Group. J Clin Oncol 2006;24:4991-7.

62. Cunningham D, Starling N, Rao S, Iveson T, Nicolson M, Coxon F, et al. Upper Gastrointestinal Clinical Studies Group of the National Cancer Research Institute of the United Kingdom Capecitabine and oxaliplatin for advanced esophagogastric cancer. N Engl J Med 2008; 358:36-46

63. Okines AF, Norman AR, McCloud P, Kang YK, Cunningham D. Metaanalysis of the REAL-2 and ML17032 trials: evaluating capecitabinebased combination chemotherapy and infused 5-fluorouracil-based combination chemotherapy for the treatment of advanced oesophagogastric cancer. Ann Oncol 2009;20:1529-34.

64. Bang YJ, Van Cutsem E, Feyereislova A, Chung HC, Shen L, Sawaki A, et al. Trastuzumab in combination with chemotherapy versus chemotherapy alone for treatment of HER2-positive advanced gastric or gastro-oesophageal junction cancer (ToGA): a phase 3, open-label, radomised controlled trial. Lancet 2010;376:687-97.

65. Thuss-Patience P, Deist T, Hinke A, et al. Irinotecan versus best supportive care as second-line therapy in gastric cancer: a randomized phase III study of the Arbeitsgemeinschaft Internistische Onkologie (AIO). J Clin Oncol 2009;27u(Supl.15):Abstract 4540.

66. Park SH, Lim DH, Park K. A multicenter, randomized phase III trial comparing second-line chemotherapy (SLC) plus best supportive care (BSC) with BSC alone for pretreated advanced gastric cancer (AGC). ASCO 2011 Abstract 4004.

67. Catalano V, Graziano F, Santini D, D'Emidio S, Baldelli AM, Rossi D, et al. Second-line chemotherapy for patients with advanced gastric cancer: who may benefit? Br J Cancer 2008;99:1402-7.

68. Ji SH, Lim do H, Yi SY, Kim HS, Jun HJ, Kim KH, et al. A retrospective analysis of second-line chemotherapy in patients with advanced gastric cancer. BMC Cancer 2009;9:110

69. Stahl M, Müller C, Koster W, Wilke H. Second-line chemotherapy of advanced disseminated gastric cancer after cisplatin, infusional 5-fluorouracil, folinic acid (PLF): benefit dependent on progression-free interval after first-line therapy. Onkologie 2005;28:499-502 